\title{
Social Support and Appearance Satisfaction Can Predict Changes in the Psychopathology Levels of Patients with Acne, Psoriasis and Eczema, before Dermatological Treatment and in a Six-Month Follow-up Phase
}

\author{
Charalambos Costeris $^{1, *}$, Maria Petridou ${ }^{2}$ and Yianna Ioannou ${ }^{1}$ \\ 1 Department of Social Sciences, School of Humanities and Social Sciences, University of Nicosia, \\ Nicosia CY 1700, Cyprus; ioannou.yi@unic.ac.cy \\ 2 Department of Psychology, University of Cyprus, Nicosia CY 1678, Cyprus; mpetri01@ucy.ac.cy \\ * Correspondence: c.kosteris@nup.ac.cy
}

Citation: Costeris, C.; Petridou, M.; Ioannou, Y. Social Support and Appearance Satisfaction Can Predict Changes in the Psychopathology Levels of Patients with Acne,

Psoriasis and Eczema, before

Dermatological Treatment and in a Six-Month Follow-up Phase. Psych 2021, 3, 259-268. https://doi.org/ $10.3390 /$ psych 3030020

Academic Editors: Jacek

C Szepietowski and Mosad Zineldin

Received: 8 May 2021

Accepted: 24 June 2021

Published: 1 July 2021

Publisher's Note: MDPI stays neutral with regard to jurisdictional claims in published maps and institutional affiliations.

Copyright: (C) 2021 by the authors. Licensee MDPI, Basel, Switzerland. This article is an open access article distributed under the terms and conditions of the Creative Commons Attribution (CC BY) license (https:// creativecommons.org/licenses/by/ $4.0 /)$.

\begin{abstract}
This was a cross-sectional study which assessed the factors that predicted changes in the levels of psychopathological symptomatology of patients with acne, psoriasis and eczema both before dermatological treatment and in a six-month follow-up phase. One hundred and eight dermatological patients (18-35 years) participated in the study; 54 with visible facial cystic acne (Group A), and 54 with non-visible psoriasis/eczema (Group B). A battery of self-report questionnaires were administered to all patients before their dermatological treatment and in a six-month follow-up phase and included: the Symptom Checklist-90 Revised (SCL-90-R), the Interpersonal Support Evaluation List (ISEL-40), the Multidimensional Body-Self Relations Questionnaire (MBSRQ-AS) and the Rosenberg Self-Esteem Scale. Multiple regression analyses revealed that patients' overall perceived social support and overall appearance satisfaction appeared to be strong predictors of the maintenance of patients' psychopathology levels, even six months after they began their dermatological treatment. Psychosocial factors such as patients' social support and appearance satisfaction could influence their psychopathology levels and the way they experienced their skin condition, before treatment and after a six-month period of time. The psychological assessment of the aforementioned factors could detect patients who would benefit from psychotherapeutic interventions in order to help them adapt to the extra burden which accompanies dermatological disorders.
\end{abstract}

Keywords: acne; appearance satisfaction; eczema; psoriasis; psychodermatology; psychopathology levels; social support

\section{Introduction}

The description of emotional difficulties in dermatological patients with acne, psoriasis and eczema has been extensively reported in the literature, mainly in studies concerning only the phase before dermatological treatment and not after its completion [1-3]. However, the factors that can predict the emotional consequences of dermatological disorders remain unexplored. The current study explores how psychosocial factors such as social support, appearance satisfaction and self-esteem in dermatological patients with acne, psoriasis and eczema can act as key factors, which can be used by dermatologists as indicators of how a patient experiences their dermatological disorder.

Firstly, the literature shows that social support is a serious factor related to how a patient can handle the bio-psychological changes that occur to their body [4,5]. The printed information available to patients from their doctor, the support of their family with whom they can communicate what they experience [6], but also the activities (hobbies) with which they relax significantly reduce the anxiety and pain that accompany a skin disorder [7]. There is limited research focusing on how social support affects the emotional state and 
psychopathology levels of patients with acne, psoriasis and eczema [8] while most focus on patients' overall quality of life and general functionality [9-12].

In addition, the way that young patients perceive their body, especially in the case of dermatological disorders, is very important, since satisfaction with their appearance is experienced through the skin $[13,14]$. If the dermatological disorder is located on a visible part of the body or if it affects a body part for a long period of time, the patient may experience dissatisfaction with their body image [15]. Therefore, dermatological disorders can function as a traumatic experience that affects both how happy the patient is with their appearance and the way they interact with others [16]. Moreover, dermatological patients often report that others may perceive them as disgusting and not good enough, due to the appearance of their skin condition [16,17], while these attitudes may affect the way that patients at young developmental stages perceive their bodies. Negative body image therefore is linked with feelings of shame, anxiety and fear, which if left for long periods of time are able to affect both the mood and the general mental health of patients [18-21].

Another factor associated with appearance dissatisfaction in dermatological disorders which have an onset at a young age is self-esteem [22]. Self-esteem develops under the attitudes that the individual has about themselves, but always in combination with the attitudes that others (peers, family) have towards them [23]. Thus, in the case of young patients with dermatological disorders, who experience appearance-related teasing and bullying, self-esteem can be irreparably affected [16]. These experiences are rarely communicated, due to feelings of shame that accompany them [24]. In these cases, the role of dermatologists is crucial, as they may be the first individual who comes in contact with these patients. A dermatologist's typical questions can therefore easily detect how patients' self-esteem is affected by a skin condition, but also its psychosocial emotional consequences [25]. Research findings indicate that dermatological disorders such as acne can be experienced by some patients as a traumatic factor [9], while it is interrelated with both emotional difficulties and low self-esteem [26-28]. However, there are conflicting findings that suggest that after completing their dermatological treatment, acne patients self-esteem improves [29,30]. Low levels of self-esteem have also been reported in recent studies that included a sample of patients with psoriasis and eczema [16,31-33].

However, research studies focusing on how social support, appearance satisfaction and self-esteem predict changes in psychopathology levels of patients with acne, psoriasis and eczema before dermatological treatment and in a six-month follow-up phase are absent from the literature. Such research studies can initially detect the factors that influence patients' levels of distress and then serve to enable dermatologists to refer patients to psychotherapy in order to communicate their difficulties. Thus, the management of dermatological disorders will be achieved holistically, both biologically as well as psychosocially, so that patients can adapt more easily.

\section{Current Study}

This study investigated whether patients' social support, appearance satisfaction and self-esteem at the time when they sought treatment for their dermatological disorder could predict changes in their psychopathology levels. The aforementioned psychological areas were proposed in order to obtain a whole picture of the factors that can predict changes in dermatological patients' psychopathology levels, before dermatological treatment and in a six-month follow-up phase, as well as to identify the way dermatologists and clinical health psychologists can interfere in order to minimize the emotional consequences of skin disorders. Two groups of dermatological patients were recruited, since according to the literature, patients with acne (with visible skin condition), as well as with psoriasis and eczema (with non-visible localization) describe similar emotional difficulties [16,22]. The following hypotheses were made: (1) before dermatological treatment, patients' perceived social support, appearance satisfaction and self-esteem will negatively predict their general level of psychopathology; (2) patients' perceived social support, appearance satisfaction and self-esteem will also negatively predict their general level of psychopathology, 
six months after they begin their dermatological treatment. The present hypotheses were proposed as we considered that the aforementioned variables can predict changes in dermatological patients' psychopathology levels, while similar studies focusing on two groups of dermatological patients (visible or non-visible dermatological disorder) are absent from the literature.

\section{Materials and Methods}

\subsection{Study Design}

The current study is divided into two phases of psychological assessment: at the time when patients begin to receive medication prescribed by their dermatologist (prior to dermatological treatment phase) and at a six-month follow-up research phase. The study involved dermatological patients with severe visible facial cystic acne (Group A) and patients with psoriasis/eczema with non-visible anatomical localization (i.e., that is it could be covered with clothes) (Group B). Dermatologists conducted the clinical examination for the patients' diagnosis before the start of their treatment and participation in the first research phase. Dermatologists were responsible for ensuring the researchers that during the six-month follow-up patients' psoriasis or eczema was not visible. Patients were also informed that they would participate in a follow-up research phase, six months after the date they began their dermatological treatment. At the phase prior to dermatological treatment, patients with acne (Group A) were prescribed retinoids and antibiotics, while participants from Group B with psoriasis followed treatments such as immunosuppressive medications, retinoids, phototherapies, as well as topical medications. Lastly, patients with eczema (Group B) were prescribed oral medications (corticosteroids and antibiotics) and topical medications.

The criteria for exclusion of participants for the present study were the existence of any medical condition that could affect patients' appearance satisfaction, pregnancy, physical disability and difficulty in speaking or reading the Greek language. Also, in Group A, patients with any additional dermatological disorders were excluded, while in Group B, patients whose dermatological disorder was visible were excluded. The Cyprus National Bioethics Committee approved the procedure and methods of the present study (EEBK EP 2015.01.103).

\subsection{Study Population}

Recruitment and screening: Only patients who were interested in participating in the study when informed by their dermatologist were recruited. Subsequently, a written consent form was obtained by all participants from the dermatologist and the researcher arranged a meeting at his office. Participants were informed in detail about the study and especially that it included a six-month follow-up phase. Information was also given about the anonymity and confidentiality of their data, reassuring all participants about disclosure of their personal information. Prior to the dermatological treatment phase, all participants were administered a sociodemographic questionnaire as a short interview. Then a battery of self-reported questionnaires were administered to each participant which included: the Symptom Checklist 90 Revised (SCL-90-R), the Interpersonal Support Evaluation List (ISEL-40), the Multidimensional Body-Self Relations Questionnaire-Appearance Scale [MBSRQ-AS] and the Rosenberg Self-Esteem Scale. When each patient's administration was complete, the researcher sealed the package of the participant, which had a specific number and code for each Group (A or B) and informed them that the first research phase was complete. In the second research phase, six months after each patient began their dermatological treatment, the researcher contacted each patient and arranged a second meeting at his office. Then the same battery of self-completed questionnaires was administered by the researcher. 


\subsection{Measures}

\subsubsection{Sociodemographic Questionnaire and Skin Disorder Characteristics}

Patients' sociodemographics and their skin disorder characteristics before dermatological treatment were collected by a questionnaire which was created for the study. The questions collected patients' age, gender, financial and educational status, as well as information about the diagnosis and pharmacological treatment prescribed by dermatologists for their dermatological disorder, at the stage when each patient agreed to participate in the study.

\subsubsection{Symptom Checklist 90 Revised (SCL-90-R)}

This is a self-report questionnaire for individuals older than 13 years. It was administered to all patients at both research phases, before their dermatological treatment and in a six-month follow-up phase. The questionnaire consists of 90 items which refer to mental and physical symptoms that comprise 9 subscales: somatization, obsessive compulsive, interpersonal sensitivity, depression, anxiety, anger-hostility, phobic anxiety, paranoid ideation, and psychoticism. All items are rated on a five-degree Likert scale of distress (not at all, a little bit, moderately, quite a bit, extremely) [34]. Psychopathology levels for the current study were assessed by the General Severity Index (GSI) of the SCL-90-R, which is the average score for all items and indicates the overall psychological distress. The questionnaire's scales' internal reliability ranged from 0.74 to 0.90 . The SCL-90-R has been translated, validated and approved for use in the Greek population in previous studies [35].

\subsubsection{Interpersonal Support Evaluation List (ISEL-40)}

Overall social support of patients was assessed using the ISEL-40 at both research phases: before their dermatological treatment and in a six-month follow-up phase. The questionnaire includes 40 items ranked from 1 (probably false) to 4 (definitely true). It assesses 4 separate sections of social support by the following subscales: (a) tangible support, (b) appraisal support, (c) self-esteem support and (d) belonging support. The ISEL-40 also provides an overall support measure, which is used for the current study. The questionnaire has been translated, validated and approved for use in the Greek language [36] and the internal consistency reliability of its scales ranged from 0.81 to 0.89 .

\subsubsection{Multidimensional Body-Self Relations Questionnaire-Appearance Scale [MBSRQ-AS]}

The questionnaire consists of a 34 self-report item inventory, developed by Dr Thomas F. Cash who gave permission for its use for the present study [37]. To assess appearance satisfaction for the current study only the subscale "appearance evaluation" of the MBSRQAS was used, since it measures how a participant evaluates their appearance and indicates the level of satisfaction with their external appearance. The higher the score on this subscale, the more positively the participant evaluates their appearance. The scale includes seven items, rated on a 5-point Likert scale, ranging from 1 (definitely disagree) to 5 (definitely agree). The questionnaire has been translated, validated and approved for use in the Greek language and the internal consistency reliability of its scales ranged from 0.82 to 0.89 . In the current study the questionnaire had very good internal consistency $(\alpha=0.80)$. The MBSRQ-AS was administered to all participants at both research phases.

\subsubsection{Rosenberg Self-Esteem Scale}

The questionnaire measures overall self-esteem and was administered to all participants at both research phases. The questionnaire reflects global self-esteem through ten items. Items are rated on a 5-point Likert scale, ranging from 1 (strongly disagree) to 5 (strongly agree). The higher the general score on the questionnaire, the higher the participant's self-esteem [38]. The questionnaire has been translated, validated and approved for use in a Greek population and its scales' consistency reliability in the current study ranged from 0.82 to 90 . 


\subsection{Statistical Analyses}

The statistical analyzes were conducted using SPSS version 22 (https://www.ibm. $\mathrm{com} /$ support/pages/downloading-ibm-spss-statistics-22, accessed on 14 December 2019) for Windows. In order to test the first hypothesis, whether patients' levels of psychopathology before dermatological treatment are predicted by their levels of perceived social support, appearance satisfaction and self-esteem, multiple regression analysis was performed by the enter method. Similarly, multiple regression analysis was performed by the enter method for the second hypothesis, with the abovementioned psychological factors (perceived social support, appearance satisfaction and self-esteem), as predictors for patients' levels of psychopathology six months after they had begun their dermatological treatment.

\section{Results}

\subsection{Sample Characteristics}

The sample included 108 dermatological patients who were young adults between 18 and 35 years old. All the volunteers who participated in the current study were diagnosed by their dermatologist regarding their dermatological disorders. Fifty-four $(n=54)$ patients with visible facial cystic acne were assigned to Group A (Mage $=20.21, S D=3.40)$, and fifty-four $(n=54)$ patients with non-visible psoriasis/eczema were included in Group B (Mage $=28.89, S D=5.36$ ). In total, $81.5 \%$ of acne patients and $83.5 \%$ of psoriasis and eczema patients mentioned that they had had some previous dermatological treatments in the past. For clarification, demographic information was collected from all participants (Groups A and B). However, none of the participants from Group A reported a poor economic status. All the demographic characteristics are illustrated in Table 1. Despite the fact that there were differences between the groups, Covariate Analysis (ANCOVA) revealed that the demographic characteristics of the two study's groups did not affect the outcome variables. Of the 108 patients who participated in the study, only one participant from Group B did not follow the guidelines for their dermatological treatment. The exclusion of this specific participant did not significantly affect the results of our study, and for this reason they were included in all statistical analyzes.

\subsection{Overall Perceived Social Support, Appearance Satisfaction and Self-Esteem as Predictors of Patients' General Level of Psychopathology, before Dermatological Treatment}

In order to examine whether patients' general level of psychopathology before treatment was predicted by their overall perceived social support, appearance satisfaction and self-esteem, multiple regression analysis was performed. All the above-mentioned variables were added with the enter method. The general level of psychopathology before dermatological treatment was defined as a dependent variable (See Table 2).

The analysis showed a significant contribution of the factors "appearance satisfaction" (standardized beta $(b)=-0.24, p<0.001)$ and "perceived social support" $(b=-0.01$, $p<0.001)$ as predictors for patients' general level of psychopathology before treatment. More specifically, the prediction for the dermatological patients' general level of psychopathology before treatment could be better interpreted, with variance $\left(R^{2}\right)$ of $43 \%$, by the effect of their appearance satisfaction and their perceived social support. That is, the lower the appearance satisfaction and the perceived social support of a dermatological patient appeared to be before treatment, the higher their general level of psychopathology was predicted to be.

\subsection{Overall Perceived Social Support, Appearance Satisfaction and Self-Esteem as Predictors of Patients' General level of Psychopathology, Six Months after They Began Their Dermatological Treatment}

In order to examine whether patients' perceived social support, their appearance satisfaction and self-esteem remained predictors for patients' general level of psychopathology at the follow-up research phase, multiple regression analysis was performed (See Table 3). The above-mentioned variables were added with the enter method. Patients' general level of psychopathology at the follow-up research phase was defined as a dependent variable. 
Table 1. Demographics: dermatological diagnosis and pharmacotherapy characteristics of the sample before the beginning of their dermatological treatment $(\mathrm{N}=108)$.

\begin{tabular}{|c|c|c|}
\hline & $\begin{array}{c}\text { Acne } \\
\text { (Group A } n=54)\end{array}$ & $\begin{array}{l}\text { Psoriasis/Eczema } \\
\text { (Group B n = 54) }\end{array}$ \\
\hline \multicolumn{3}{|l|}{ Demographics } \\
\hline Age & $\mathrm{M}=20.21(\mathrm{SD}=3.40)$ & $\mathrm{M}=28.89(\mathrm{SD}=5.36)$ \\
\hline \multicolumn{3}{|l|}{ Educational Level } \\
\hline Bachelor Degree & $18.5 \%$ & $57.4 \%$ \\
\hline High School & $81.5 \%$ & $42.6 \%$ \\
\hline \multicolumn{3}{|l|}{ Occupational Status } \\
\hline Unemployed & $7.4 \%$ & $16.7 \%$ \\
\hline Employees & $24.1 \%$ & $63.00 \%$ \\
\hline Undergraduate students & $33.3 \%$ & $11.1 \%$ \\
\hline Post-graduate students & $1.9 \%$ & $0 \%$ \\
\hline Soldiers & $33.3 \%$ & $9.3 \%$ \\
\hline \multicolumn{3}{|l|}{ Economic Status } \\
\hline Poor * & $0 \%$ & $3.7 \%$ \\
\hline Middle & $16.7 \%$ & $25.9 \%$ \\
\hline Good & $55.6 \%$ & $51.9 \%$ \\
\hline \multicolumn{3}{|l|}{ Status } \\
\hline Marriage & $1.9 \%$ & $38.9 \%$ \\
\hline Single & $98.1 \%$ & $54.4 \%$ \\
\hline Divorced & $0 \%$ & $3.7 \%$ \\
\hline $\begin{array}{l}\text { Diagnosis } \\
\text { Age of onset }\end{array}$ & $\mathrm{M}=15.96$ years & $\mathrm{M}=21.76$ years \\
\hline \multicolumn{3}{|l|}{ Previous Treatments } \\
\hline Dermatological & $81.5 \%$ & $83.3 \%$ \\
\hline Pharmacotherapy & $100 \%$ & $100 \%$ \\
\hline
\end{tabular}

Note $M=$ Mean, $S D=$ Standard Deviation. ${ }^{*}$ Economic status refers to the amount of monthly income. Poor status refers to the monthly income that is below the basic salary.

Table 2. Regression analysis for the variables that predict patients' general level of psychopathology before dermatological treatment.

\begin{tabular}{ccccc}
\hline Variables & $\begin{array}{c}\text { Standardized Values } \\
\text { Beta (b) }\end{array}$ & $\begin{array}{c}\text { Standard Error } \\
\text { Beta (SE B) }\end{array}$ & $\begin{array}{c}\text { Unstandardized Values } \\
\text { Beta (B) }\end{array}$ & $p$-Value \\
\hline $\begin{array}{c}\boldsymbol{R}^{2} \\
\text { Appearance }\end{array}$ & -0.24 & 0.06 & $-0.31^{*}$ & 0.43 \\
$\begin{array}{c}\text { satisfaction } \\
\text { Perceived social }\end{array}$ & -0.01 & 0.00 & $-0.39 *$ & $<0.001$ \\
$\begin{array}{c}\text { support } \\
\text { Self-esteem }\end{array}$ & -0.01 & 0.02 & -0.05 & 0.45 \\
\hline
\end{tabular}

${ }^{*}$ Note. $p$ value $<0.001$. Dependent variable: general level of psychopathology before treatment [enter method]. $R^{2}=$ the percentage (variance) that explains the relationship between dependent and independent variables.

Table 3. Regression analysis for the variables that predict patients' general level of psychopathology at the follow-up research phase.

\begin{tabular}{ccccc}
\hline Variables & $\begin{array}{c}\text { Standardized } \\
\text { Values Beta (b) }\end{array}$ & $\begin{array}{c}\text { Standard Error } \\
\text { Beta (SE B) }\end{array}$ & $\begin{array}{c}\text { Unstandardized Values } \\
\text { Beta (B) }\end{array}$ & $p$-Values \\
\hline $\begin{array}{c}\boldsymbol{R}^{2} \\
\text { Appearance }\end{array}$ & -0.15 & 0.05 & $-0.21^{*}$ & $<0.64$ \\
$\begin{array}{c}\text { setisfaction } \\
\text { seived social }\end{array}$ & -0.02 & 0.00 & $-0.64 *$ & $<0.001$ \\
support & -0.00 & 0.01 & -0.00 & 0.94 \\
\hline
\end{tabular}

${ }^{*}$ Note. $p$ value $<0.001$. Dependent variable: general level of psychopathology at the follow up research phase [enter method]. $R^{2}=$ the percentage (variance) that explains the relationship between dependent and independent variables.

The analysis showed a significant contribution of the factors "perceived social support" $(b=-0.02, p<0.001)$ and "appearance satisfaction" $(b=-0.15, p<0.001)$ for the prediction 
of patients' general level of psychopathology at the follow-up phase. More specifically, the prediction of a dermatological patient's general level of psychopathology at the follow-up phase can be better interpreted, with a variance of $64 \%\left(R^{2}\right)$, by the effect of their perceived social support and their appearance satisfaction than by any other scale. That is, the lower a patient's perceived social support and appearance satisfaction appear to be six months after they began their dermatological treatment, the higher their general level of psychopathology was predicted to be.

For the first hypothesis it was found conclusively that perceived social support and appearance satisfaction predict dermatological patients' levels of psychopathology before treatment $(p<0.001)$; for the second hypothesis, it was found that perceived social support and appearance satisfaction predict dermatological patients' levels of psychopathology at the follow-up phase $(p<0.001)$.

More specifically, the lower the perceived social support and appearance satisfaction of the dermatological patient before treatment, the higher their general level of psychopathology was predicted to be. In particular, patients' perceived social support and appearance satisfaction were strong predictors of the maintenance of their general levels of psychopathology, even six months after they began their dermatological treatment.

\section{Discussion}

There are only a few studies which investigate the role of perceived social support and its influence in dermatological patients' lives [12,14,25]. However, studies that investigate perceived social support, appearance satisfaction and self-esteem as factors which predict changes in dermatological patients' levels of psychopathology, before dermatological treatment and in a six-month follow-up phase, by including two groups of patients (with visible and non-visible skin condition) are so far absent in the literature.

The results of the present study prove that perceived social support predicts changes in dermatological patients' psychopathology levels, while adding that their overall appearance satisfaction also seems to be an important predictor. More specifically, the lower the perceived social support and the overall appearance satisfaction of the dermatological patient before dermatological treatment, the higher their psychopathology levels are predicted to be. The contribution of the present research to the literature is evident in the fact that these two factors are examined together for the first time for their predictive role in dermatological patients' psychopathology levels and at two research phases: before dermatological treatment and in a six-month follow-up phase.

In conclusion, patients' overall perceived social support and overall appearance satisfaction appear to be strong predictive factors influencing the maintenance of their general level of psychopathology, even six months after the beginning of their dermatological treatment. Therefore, these two factors seem to act protectively in the onset of psychopathology, both before dermatological treatment and in a six-month period of time, while they can facilitate the experience of dermatological disorder for patients. The desire to receive dermatological services can therefore be interpreted as an external request of patients, but the psychological request may be to minimize the dissatisfaction with their external appearance, as well as to allow them to accept their body as it is and connect with others through personal contact. Therefore, the concept of dermatological intervention is closely related to the desire of patients to modify their body and appearance, but also to be able to interact more comfortably with others. The desire to change their appearance is manifested as a kind of indicator of the desire to contact others, revealing the emotional difficulty that arises from coping with the experience of dermatological disorder. Patients' psychological alienation from others can be bridged through the initial contact with their dermatologist, in order to create a new improved image of their physical "ego". For this reason, the dermatologist appears to be the first reference person who can act protectively towards patients with acne, eczema and psoriasis when trained to be able to detect patients' internal difficulties during their arrival at his office. Therefore, dermatologists' collaboration with clinical health psychologists, as well as training with easy-to-use clinical tools, could have 
a protective effect on patients, resulting in improving their adaptation to dermatological disorders and reducing their psychopathology levels.

Current results are in line with prior studies $[12,14]$ which report that low social support and negative body image were associated with high levels of depression in patients with psoriasis and that social support is effective in depressive symptomatology. In addition, the present study agrees with recent findings that high levels of social support in dermatological patients were associated with lower levels of aggression [39], with the predictive role of body image in depression in patients with psoriasis [40], as well as with the predictive role of social support in the psychological distress of patients with psoriasis and atopic dermatitis [41].

In the present study however, the predictive role of gender in the existence of depression was not observed, as found in the studies of Janowski et al. [12] and Wojtyna et al. [14]. Some reasons for this discrepancy may be that the present study focused mainly on overall levels of psychopathology and not on individual psychopathology scales. Moreover, the current study's experimental design included two phases of measurement, before treatment with a dermatologist and in a six-month follow-up phase. Lastly, the sample age of the current study included participants from 18 to 35 years old, whilst the sample of aforementioned studies included older patients.

\section{Limitations}

The fact that the current research collected patients from only two cities of Cyprus, as well as the fact that the tools used were self-reported questionnaires, make its conclusions difficult to be generalized to all dermatological patients with acne, psoriasis and eczema. Another limitation is the sample size, which does not allow us to investigate in depth how all dermatological patients might experience their skin condition. Moreover, a more diverse sample of dermatological patients from various cultures is necessary in order to examine if socio-cultural factors may also influence patients' body image and selfesteem. Furthermore, a patient from our sample informed their dermatologist that they discontinued their medication on the fifth month, whilst they frequently visited their office for consultations. Although they did not follow their pharmacological treatment as prescribed by their dermatologist, the participant did not wish to drop out from the study and wished to participate at the six-month follow-up research phase. Since patients' noncompliance might have influenced our results, we suggest that in future research attention should also be paid to the area of non-compliance with the dermatologist's guidelines.

Lastly, the current study recruited only patients with acne whose skin condition was visible and excluded those with acne on body parts that are not visible (back, chest). Similarly, the study recruited only participants with psoriasis and eczema whose skin condition was non-visible and excluded those with visible psoriasis or eczema (i.e., on the face, hands, or neck). For this reason, current results need to be interpreted with caution. Future studies may address this issue by including patients in their sample who share the same diagnosis and dividing them in two groups: with a visible skin disorder and with a non-visible skin disorder. Another reason why current results should be interpreted with caution is the fact that dermatologists confirmed to the researcher that patients' psoriasis or eczema was not visible during the six-month treatment. The absence of a research tool at the follow-up phase to ensure that patients did not experience flare-ups during the six-month treatment is one of the limitations of our study.

\section{Conclusions}

Current findings show that psychosocial factors such as social support and appearance satisfaction appear to be strong predictors of the maintenance of patients' psychopathology levels, even six months after the beginning of their dermatological treatment. For this reason, psychosocial interventions should be designed with the collaboration of dermatologists and clinical/health psychologists in order to first detect vulnerable patients with acne, psoriasis and eczema. Lastly, it is important for dermatologists to ask their 
patients questions on the abovementioned two areas, in order to suggest psychotherapeutic interventions, in an attempt to encourage them to develop better adaptation skills.

Author Contributions: Conceptualization, C.C. and Y.I.; methodology, C.C. and Y.I.; validation, C.C; formal analysis, C.C.; Y.I. and M.P; investigation, C.C.; resources, C.C.; data curation, C.C.; writing—original draft preparation, C.C.; writing—review and editing, C.C.; Y.I. and M.P.; visualization, C.C.; supervision, Y.I.; project administration, C.C. and Y.I. All authors have read and agreed to the published version of the manuscript.

Funding: The authors received no financial support for the study, authorship and publication of this article.

Institutional Review Board Statement: The study was conducted according to the guidelines of the Declaration of Helsinki, and approved by the Cyprus National Bioethics Committee (EEBK ЕП 2015.01.103).

Informed Consent Statement: For inclusion of each participant in this study, a written informed consent was obtained.

Data Availability Statement: The data presented in the study are available on request from the corresponding author.

Acknowledgments: We would like to thank all patients who participated in the study, as well as all Dermatologists for their research vision, who helped us recruit our sample.

Conflicts of Interest: None declared by the authors.

\section{References}

1. Gupta, M.A.; Gupta, A.K. Cutaneous Body Image Dissatisfaction and Suicidal Ideation: Mediation by Interpersonal Sensitivity. J. Psychosom. Res. 2013, 75, 55-59. [CrossRef]

2. Gupta, M.A.; Gupta, A.K. Psychodermatology: An Update. J. Am. Acad. Dermatol. 1996, 34, 1030-1046. [CrossRef]

3. Gupta, M.A.; Gupta, A.K.; Ellis, C.N.; Koblenzer, C.S. Psychiatric Evaluation of the Dermatology Patient. Dermatol. Clin. 2005, 23, 591-599. [CrossRef]

4. Berkman, L.F.; Glass, T.; Brissette, I.; Seeman, T.E. From Social Integration to Health: Durkheim in the New Millennium. Soc. Sci. Med. 2000, 51, 843-857. [CrossRef]

5. Wang, H.H.; Wu, S.Z.; Liu, Y.Y. Association between Social Support and Health Outcomes: A Meta-analysis. Kaohsiung J. Med. Sci. 2003, 19, 345-350. [CrossRef]

6. Thompson, A.; Kent, G. Adjusting to Disfigurement: Processes Involved in Dealing with Being Visibly Different. Clin. Psychol. Rev. 2001, 21, 663-682. [CrossRef]

7. Moos, R.H.; Moos, B.S. Life Stressors and Social Resources Inventory-Adult Form: Professional Manual; PAR: Odessa, FL, USA, 1994.

8. Livea Lalji, T.L.; Anto, M.M.; Shojan, A.; Sebastian Criton, V.J. Self-Efficacy, Perceived Social Support and Quality of Life of Females with Acne and Eczema. Res. J. Pharm. Biol. Chem. Sci. 2015, 6, 1328-1331.

9. Al Robaee, A.A. Assessment of General Health and Quality of Life in Patients with Acne Using a Validated Generic Questionnaire. Acta Derm. Alp. Panon. Adriat. 2009, 18, 157-164.

10. Krejci-Manwaring, J.; Kerchner, K.; Feldman, S.R.; Rapp, D.A.; Rapp, S.R. Social Sensitivity and Acne: The Role of Personality in Negative Social Consequences and Quality of Life. Int. J. Psychiatry Med. 2006, 36, 121-130. [CrossRef]

11. Khoury, L.R.; Danielsen, P.L.; Skiveren, J. Body Image Altered by Psoriasis. A Study Based on Individual Interviews and a Model for Body Image. J. Dermatol. Treat. 2014, 25, 2-7. [CrossRef]

12. Janowski, K.; Steuden, S.; Pietrzak, A.; Krasowska, D.; Łukasz, K.; Gradus, I.; Chodorowska, G. Social Support and Adaptation to the Disease in Men and Women with Psoriasis. Arch. Dermatol. Res. 2012, 304, 421-432. [CrossRef]

13. Murray, C.D.; Rhodes, K. Nobody Likes Damaged Goods: The Experience of Adult Visible Acne. Br. J. Health Psychol. 2005, 10, 183-202. [CrossRef]

14. Wojtyna, E.; Łakuta, P.; Marcinkiewicz, K.; Bergler-Czop, B.; Brzezińska-Wcisło, L. Gender, Body Image and Social Support: Biopsychosocial Determinants of Depression among Patients with Psoriasis. Acta Derm. Venereol. 2017, 97, 91-97. [CrossRef]

15. Magin, P.; Adams, J.; Heading, G.; Pond, D. 'Perfect Skin', the Media and Patients with Skin Disease: A Qualitative Study of Patients with Acne, Psoriasis and Atopic Eczema. Aust. J. Prim. Health 2011, 17, 181-185. [CrossRef]

16. Magin, P.; Adams, J.; Heading, G.; Pond, D.; Smith, W. Experiences of Appearance-Related Teasing and Bullying in Skin Diseases and Their Psychological Sequelae: Results of a Qualitative Study. Scand. J. Caring Sci. 2008, 22, 430-436. [CrossRef]

17. Lahousen, T.; Kupfer, J.; Gieler, U.; Hofer, A.; Linder, M.D.; Schut, C. Differences between Psoriasis Patients and Skin-Healthy Controls Concerning Appraisal of Touching, Shame and Disgust. Acta Derm. Venereol. 2016, 96, 78-82. [CrossRef] [PubMed]

18. Babayan, K.R.; Mkrtchyan, A.M.; Manukyan, E.H.; Hovhannisyan, H.A. Stigmatization of Patients with Some Dermatoses. N. Armen. Med. J. 2008, 2, 14-19. 
19. Hong, J.; Koo, B.; Koo, J. The Psychosocial and Occupational Impact of Chronic Skin Disease. Dermatol. Ther. 2008, 21, 54-59. [CrossRef]

20. Wahl, A.K.; Gjengedal, E.; Hanestad, B.R. The Bodily Suffering of Living with Severe Psoriasis: In-Depth Interviews with 22 Hospitalized Patients with Psoriasis. Qual. Health Res. 2002, 12, 250-261. [CrossRef]

21. Picardi, A.; Lega, I.; Tarolla, E. Suicide Risk in Skin Disorders. Clin. Dermatol. 2013, 31, 47-56. [CrossRef] [PubMed]

22. Urpe, M.; Pallanti, S.; Lotti, T. Psychosomatic Factors in Dermatology. Dermatol. Clin. 2005, 23, 601-608. [CrossRef]

23. Trzesniewski, K.H.; Donnellan, M.B.; Robins, R.W. Development of Self-Esteem. In Self-Esteem; Current Issues in Social Psychology; Psychology Press: New York, NY, USA, 2013; pp. 60-79.

24. Magin, P.; Adams, J.; Heading, G.; Pond, D.; Smith, W. Psychological Sequelae of Acne Vulgaris: Results of a Qualitative Study. Can. Fam. Physician 2006, 52, 978-979. [PubMed]

25. Bewley, A.; Taylor, R.E.; Reichenberg, J.S.; Magid, M. Practical Psychodermatology; Wiley Online Library: Hoboken, NJ, USA, 2014.

26. Uslu, G.; Şendur, N.; Uslu, M.; Şavk, E.; Karaman, G.; Eskin, M. Acne: Prevalence, Perceptions and Effects on Psychological Health among Adolescents in Aydin, Turkey. J. Eur. Acad. Dermatol. Venereol. 2008, 22, 462-469. [CrossRef] [PubMed]

27. Tasoula, E.; Gregoriou, S.; Chalikias, J.; Lazarou, D.; Danopoulou, I.; Katsambas, A.; Rigopoulos, D. The Impact of Acne Vulgaris on Quality of Life and Psychic Health in Young Adolescents in Greece: Results of a Population Survey. An. Bras. Dermatol. 2012, 87, 862-869. [CrossRef]

28. Mallon, E.; Newton, J.N.; Klassen, A.; Stewart-Brown, S.L.; Ryan, T.J.; Finlay, A.Y. The Quality of Life in Acne: A Comparison with General Medical Conditions Using Generic Questionnaires. Br. J. Dermatol. 1999, 140, 672-676. [CrossRef]

29. Fakour, Y.; Noormohammadpour, P.; Ameri, H.; Ehsani, A.H.; Mokhtari, L.; Khosrovanmehr, N. The Effect of Isotretinoin (Roaccutane) Therapy on Depression and Quality of Life of Patients with Severe Acne. Iran. J. Psychiatry $2014,9,237$.

30. Šimić, D.; Penavić, J.Z.; Babić, D.; Gunarić, A. Psychological Status and Quality of Life in Acne Patients Treated with Oral Isotretinoin. Psychiatr. Danub. 2017, 29 (Suppl. 2), 104-110. [PubMed]

31. Rieder, E.; Tausk, F. Psoriasis, a Model of Dermatologic Psychosomatic Disease: Psychiatric Implications and Treatments. Int. J. Dermatol. 2012, 51, 12-26. [CrossRef] [PubMed]

32. Aydin, E.; Atis, G.; Bolu, A.; Aydin, C.; Karabacak, E.; Dogan, B.; Ates, M.A. Identification of Anger and Self-Esteem in Psoriasis Patients in a Consultation-Liaison Psychiatry Setting: A Case Control Study. Psychiatry Clin. Psychopharmacol. 2017, 27, 216-220. [CrossRef]

33. Nazik, H.; Nazik, S.; Gul, F.C. Body Image, Self-Esteem, and Quality of Life in Patients with Psoriasis. Indian Dermatol. Online J. 2017, 8, 343. [CrossRef]

34. Derogatis, L.R.; Savitz, K.L. The SCL-90-R, Brief Symptom Inventory, and Matching Clinical Rating Scales. In The Use of Psychological Testing for Treatment Planning and Outcomes Assessment, 2nd ed.; Lawrence Erlbaum Associates Publishers: Mahwah, NJ, USA, 1999; pp. 679-724.

35. Donias, S.; Karastergiou, A.; Manos, N. Standardization of the Symptom Checklist-90-R Rating Scale in a Greek Population. [Standardization of the Symptom Checklist-90-R Rating Scale in a Greek Population]. Psychiatriki 1991, 2, 42-48.

36. Adonis, M.N.; Demetriou, E.A.; Skotinou, A. Acute Stress Disorder in Greek Cypriots Visiting the Occupied Areas. J. Loss Trauma 2018, 23, 15-28. [CrossRef]

37. Cash, T.F. User's Manual for the Multidimensional Body-Self Relations Questionnaire; Old Dominion University: Norfolk, VA, USA, 2000.

38. Rosenberg, M. Rosenberg Self-Esteem Scale (RSE). Acceptance and Commitment Therapy. Meas. Package 1965, $61,52$.

39. Coneo, A.M.C.; Thompson, A.R.; Lavda, A. The Influence of Optimism, Social Support and Anxiety on Aggression in a Sample of Dermatology Patients: An Analysis of Cross-Sectional Data. Br. J. Dermatol. 2017, 176, 1187-1194. [CrossRef] [PubMed]

40. Lakuta, P.; Marcinkiewicz, K.; Wojtyna, E. The Biopsychosocial Predictors of Depression among Patients with Psoriasis. Eur. Psychiatry 2015, 30, 1. [CrossRef]

41. Evers, A.W.M.; Lu, Y.; Duller, P.; Van Der Valk, P.G.M.; Kraaimaat, F.W.; Van De Kerkhof, P.C.M. Common Burden of Chronic Skin Diseases? Contributors to Psychological Distress in Adults with Psoriasis and Atopic Dermatitis. Br. J. Dermatol. 2005, 152, 1275-1281. [CrossRef] 